\title{
Videophone-based multimodal home telecare support system for patients with diabetes
}

\section{$\operatorname{AUTHOR}(S)$ :}

Kubota, Masakazu; Hosoda, Kiminori; Eguchi, Kyoko; Furuya, Ayana; Nishijima, Yuki; Nakao, Kazuwa; Kinoshita, Ayae

\section{CITATION:}

Kubota, Masakazu ...[et al]. Videophone-based multimodal home telecare support system for patients with diabetes. Diabetology International 2013, 4(1): 52-59

\section{ISSUE DATE:}

2013-03

URL:

http://hdl.handle.net/2433/173361

\section{RIGHT:}

The final publication is available at www.springerlink.com; This is not the published version. Please cite only the published version.; この論文 は出版社版でありません。引用の際には出版社版をご確認ご利用くだ さい。 
Videophone-based multimodal home telecare support system for patients with diabetes

Running title: Videophone-based multimodal communication

Masakazu Kubota $^{1)}$, Kiminori Hosoda ${ }^{1), 2)}$, Kyoko Eguchi ${ }^{3)}$, Ayana Furuya ${ }^{1)}$, Yuki Nishijima ${ }^{1)}$, Kazuwa Nakao $^{2)}$, Ayae Kinoshita ${ }^{1)}$

${ }^{1)}$ Department of human health sciences, Graduate school of medicine, Kyoto University, Kyoto 606-8507, Japan

${ }^{2)}$ Department of medicine and clinical science, Graduate school of medicine, Kyoto University, Kyoto 606-8507, Japan

${ }^{3)}$ Department of geriatric nursing, School of nursing, Osaka Prefecture University, Habikino 583-8555, Japan

Type of manuscript: Original article

Correspondence to Masakazu Kubota Ph.D., Department of Human Health Sciences, Graduate School of Medicine, Kyoto University, 53 Shogoin Kawahara-cho, Sakyo-ku, Kyoto, 606-8507, Japan

Telephone: $+81(75)$ 751-3927

FAX: +81 (75) 751-3927

E-mail: kubota.masakazu.5w@kyoto-u.ac.jp 


\section{Abstract}

Aims: We conducted an intervention study to clarify how effectively telemedicine system using multi-functional videophone could be used in lifestyle guidance, with a special focus on diet for diabetic patients cared for at home.

Methods: Patients were assigned to a 3-month intervention group or to a usual care group. In the intervention group, patients and a medical professional communicated bi-directionally through a videophone-based communication system for 30 minutes, once a week. The participants were encouraged to send pictures of each meal online, through the videophone system, in real time.

Results: Intra-subjective comparison, the 3-month intervention program resulted in a significant decrease in the Body Weight (BW) $(p<0.0005)$, and the average HbA1C level $(p<0.005)$ compared to before intervention program. Three months after the conclusion of the intervention program, the average $\mathrm{HbA1C}$ level returned to almost the same levels as it was at the pre-intervention stage $(p<0.05)$. In usual care group, the average $\mathrm{HbA1C}$ level did not change significantly for six months.

Conclusions: 3-month intensive communication using the multimodal videophone system led to a significant decrease in BW and average HbA1C level. This novel bi-directional communication is useful for improving conditions of diabetes, BW, and hyperglycemia of homecare diabetes patients, thus, -reducing cardiovascular risk.

Keywords: Videophone; Multimodal; Telecare; Homecare.

\section{Introduction}

It is estimated that all around the world, the number of adults with diabetes will rise from 135 million in 1995 to 300

million in the year 2025 [1]. In Japan too, the prevalence of type 2 diabetes and prediabetes has been increasing in the 
recent decades. In 2007, approximately 8.9 million people were estimated to have diabetes. Also, there were approximately 13.2 million people with possibilities of developing diabetes [2]. The pathogenesis of type 2 diabetes is characterized by increased peripheral insulin resistance and decreased insulin secretion, which lead to complications such as diabetic neuropathy, nephropathy, and retinopathy. Thus, it is important for patients with diabetes to prevent complications of diabetes by improving glycemic control through sequential therapy. To date, a sedentary lifestyle and Westernized high-calorie diet, which result in overweight, have been considered to be associated with an increased risk for the development of diabetes [3-5]. Therefore, the introduction of weight management, energy-restricted diet, and a physically active lifestyle, is thought to be the primary approach in the treatment of diabetes. A lot of studies demonstrated that lifestyle interventions, including energy-restricted diet, exercise habit, and cognitive behavior therapy, would yield significant behavioral improvements, as well as weight loss and better glycemic control [6-10].

In Japan, lifestyle education for diabetes is mainly conducted in hospitals. Patients with diabetes are hospitalized for education for a short time and given self-management training, which includes dietary intervention, exercise therapy, and drug therapy, under the direction of professionals such as doctors, nurses, and nutritionists in hospitals. After the in-hospital training program, the patients with diabetes are expected to observe the self-care program at home as well. However, the brief training session is not sufficient to rectify their dietary behavior problems, with the hospital visits being only once a month or once in two months [11]. It can be challenging for patients to accept that it is worthwhile making significant lifestyle changes to tackle various problems such as glycemic control, unbalanced diet, and sedentary lifestyle.

Recently, with the spread of internet-based technology, the number of people using information communication technology (ICT) devices has increased dramatically. ICT devices are gradually being introduced in the field of healthcare as a telemedicine system tool. Previous studies from our laboratory documented evidence that a 
videophone-based intensive communication is useful for cognitive rehabilitation of dementia patients and for the psychological care of their caregivers [12]. Thanks to its portability, ICT devices are now used in telemedicine to manage chronic diseases, including diabetes. Some studies evaluated weight maintenance and glycemic control program delivered via the Internet, telephone, and e-mail intervention [13-16]. Of these, two recent studies by Harvey-Berino J et al. [13] and Noh JH et al. [16] have reported whether medical interventions using ICT devices were effective in treating patients with diabetes. The former report has indicated that the Internet was an effective vehicle for promoting long-term clinically significant levels of weight loss. The latter report has shown that HbA1c and postprandial glucose levels were significantly decreased by a web-based intervention at six months post-initiation in patients with type 2 diabetes. Thus, ICT devices have tremendous potential as tools that offer health benefits. Therefore, we have to pursue the most effective ICT-based approach and learn how to maximize its use to help diabetes patients regain and maintain a balanced lifestyle. However, some of the patients, particularly elderly people, are likely to have some difficulties in operating computer-based ICT devices. As type 2 diabetes is common in older adults [17], it may be expected that many may express great anxiety about using ICT devices - compared to younger adults [18]. Recently, innovative multi-functional devices have been developed as a new communication tool, equipped with not only a telephone but also an Internet-based videophone and other multimodal functions. The main characteristics of the multimodal videophone equipment - is its user-friendliness. It can be easily operated using a touch panel, has a relatively large display and requires no knowledge of computers. Considering the advantages of these innovative devices, we felt that an effective approach utilizing these tools in the healthcare field should be thoroughly evaluated.

In the present study, we conducted an intervention study to clarify how effectively bi-directional communication system with multimodal functions was used in lifestyle guidance, with special focus on diet, for diabetic patients cared 
for at home. Based on data collected using the real time videophone system, which can transmit information on body

weight, diet record, and attached pictures of the meals, we conclude that these new ICT-based interventions showed a significant effect on control of diabetes, thus reducing the number of regular hospital visits. The interactive nature of this Internet-based communication will surely be an appealing mode of telemedicine in treating homecare patients in the future.

\section{Materials and Methods}

\subsection{Subjects}

Participants who were diagnosed with type 2 diabetes were recruited from an outpatient section at the Department of Medicine and Clinical Science, Kyoto University Hospital. Twenty patients with diabetes were randomly assigned to a 3-month intervention group or to a usual care group (Table 1). Ten subjects with type 2 diabetes ( $63 \pm 2$ years, four males and six females) were invited to participate in this interventional study. The other ten patients ( $65 \pm 3$ years, four males and six females) were treated on an outpatient basis once in one or two months as usual. Their eligibility was assessed based on their medical history. Both intervention group and control group were presented to a diabetes specialist once in one or two months. Only telephonic participants were prompted by us to receive the ICT-based intervention. Before the recruitment and before they gave their voluntary consent to participate in the study, they were informed about the nature, purpose, and possible risks of the study. All the subjects with diabetes were treated with oral hypoglycemic agents and medical nutritional therapy. All the subjects had had stable BW for at least three months prior to their participation in the study. Exclusion criteria were as follows: psychological problem, disordered recognition, impaired visual acuity, disabled hands restricting or prohibiting the use of the videophone system, impaired hearing. Participants who did not have a Nippon Telegraph and Telephone West 
Corporation $\hat{Q}$ local cable systems in their home were also excluded since this was a requirement for the videophone installation. The study protocol was approved by the ethical committee of the Kyoto University Graduate School of Medicine (approval number E661) and all individuals provided written informed consent after the study purpose and design were explained to them.

\subsection{Telemedicine system}

The telemedicine system used in this study consisted of a central hospital unit and peripheral units (at patientsôhomes), connected by multimodal videophones (Fletô phone VP1000; Nippon Telegraph and Telephone West Corporation, Japan) via optical cable. The multimodal videophone was installed at each patientô home before the nursing intervention was started. The main characteristic of the multimodal videophone equipment was its user-friendliness. It could be easily operated using a touch panel and had a relatively large display. Thus, it could be easily used even by elderly people. It could be operated without any difficulty after a 30-min guidance session. Furthermore, this multimodal system had a function which was able to send and display pictures of each meal taken by the patients and a graph file of the BW data on a screen. The price of the multimodal videophone is 200 dollars and the monthly telecommunication costs only a flat rate of 40 dollars.

\subsection{Study design}

Nguyen et al. [19] suggested that weight loss and obesity prevention are important medical targets of intervention in the effort to reduce the impact of diabetes on the health-care field. According to the recommendations of the Japan Diabetes Society (JDS) and Japan Society for the Study of Obesity (JASSO), an ideal daily calorific intake (kcal/day) is estimated from the following formula: ideal body weight (IBW, $\mathrm{kg}$ ) x 25-35 (kcal) depending on daily activity. IBW 
is defined as the weight that equals 22 times the square of the height $(\mathrm{m})[20,21]$. Nakajima et al. [22] concluded that the diet therapy recommended by JDS and JASSO can be a useful and simple program for the control of BW and hyperglycemia in daily life. In line with their instructions, we encouraged a diabetic patient to eat properly, by communicating via videophone, with visual and live messages, and also using examples based on recommended calorific intake. We also encouraged, physical activities.

For a period of three months, the patients in the intervention group were instructed to record their BW, contents of meal, and exercise situation every day. They were instructed to take and save digital photos of every meal. During the intervention, they communicated bi-directionally on a one-to-one basis with a staff nurse through the videophone system for 30 minutes, once a week (Figure 1). The nurse facilitated the patientô problem-solving abilities from the perspective of diabetes self-management, based on a graph of weight history, drug compliance, and weekly exercise habit. Additionally, taking advantage of a multimodal system which can send and display pictures and a graph file of the BW data, the staff nurse checked the attached pictures of every meal; this was done jointly with the patients through the videophone system in real time. After assessing the adequacy of the dietary intake, the staff nurse advised the patients on the amount and types of food that they should eat by drawing marks, nothing the approximate calorie contents of the meal, and by writing a few comments on a display directly (Figure 2). The period of intervention was followed by three months of withhold intervention. The patients were instructed to return to their usual lifestyle in self-care while receiving outpatient treatment on a monthly basis during this period. During this time control patients were treated on an outpatient basis once in one or two months as usual.

\subsection{Measurement}

Medical diagnosis, the duration of diabetes, height, fasting blood glucose level (FBG), HbA1c, total 
cholesterol, triglycerides (TG), low density lipoprotein-cholesterol (LDL-cholesterol), and high density lipoprotein-cholesterol (HDL-cholesterol) at baseline were obtained from the patientsômedical records. BMI was calculated by measuring weight in kilograms and height in meters, and then computing the following formula: weight (kg) -/- height $\left(\mathrm{m}^{2}\right)$. Blood was collected after an overnight fast of at least 12 hours, when the participants returned for follow-up visit at 1, 2, 3, and 6 months after the study initiation. Daily weight was measured before breakfast, without shoes or heavy clothing and using the same weighing scale in the patientô home.

\subsection{Statistical analysis}

All data were expressed as means \pm S.E. Data were analyzed using the Statistical Package for Social Science for Windows version 16.0 (SPSS Japan, Tokyo, Japan). All parameters were evaluated using the paired $t$-test. P-value less than 0.05 was considered to be statistically significant.

\section{Results}

\subsection{Baseline characteristics}

All the patients, who were diagnosed with diabetes by the attending doctor, participated in this study. The patient information is shown in Table 1. All the patients had uncontrolled diabetes with high FBG levels (intervention; $134.7 \pm 12.5 \mathrm{mg} / \mathrm{dl}$, control; $157.0 \pm 18.7 \mathrm{mg} / \mathrm{dl}$ ) and HbAlc levels (intervention; $7.4 \pm 0.3 \%$, control; $7.5 \pm 0.2 \%$ ) despite being educated on the diet to be followed, exercise therapy, and the use of oral anti-diabetes drugs, as an outpatient, over the years. Most of the participants showed normal TG levels (intervention; $134.6 \pm 24.9 \mathrm{mg} / \mathrm{dl}$, control; $106.6 \pm 20.7 \mathrm{mg} / \mathrm{dl}$ ), total cholesterol levels (intervention; $183.7 \pm 12.0 \mathrm{mg} / \mathrm{dl}$, control; $185.3 \pm 9.1 \mathrm{mg} / \mathrm{dl}$ ), HDL-cholesterol levels (intervention; $51.1 \pm 4.5 \mathrm{mg} / \mathrm{dl}$, control; $51.9 \pm 4.0 \mathrm{mg} / \mathrm{dl}$ ), and LDL-cholesterol levels 
(intervention; $100.1 \pm 7.5 \mathrm{mg} / \mathrm{dl}$, control; $101.8 \pm 7.8 \mathrm{mg} / \mathrm{dl}$ ) as shown in Table 1 .

\subsection{The effects of videophone-based intervention}

During the session once a week, the staff nurse communicated with the patients on a one-to-one basis. Taking advantage of multimodal functions of the touch panel system of a videophone, the nurse examined and remediated contents of meals and intake of food through the videophone system in real time. To provide nutritional advice, the nurse calculated the numbers of calories in their meals during the session and wrote them directly on the display (Figure 2). Based on the amount of caloric intake and nutrition, the nurse advised the patients on the amount and types of food they should eat in the concrete. In addition, the nurse showed the line graph of the change in their BW on the display and evaluated the effect of dietary and exercise habits. If the result of the weight change was not satisfactory, the nurse analyzed the reason for this and encouraged the patient to follow adequate dietary and fluid intake. During the session, the patient was given advice on exercise habits as well.

Intra-subjective comparison, the 3-month intervention program resulted in a significant decrease in BW $(-3.3 \pm$ $0.6 \%, \mathrm{p}<0.0005$, Figure 3), BMI (from $26.8 \pm 1.5 \mathrm{~kg} / \mathrm{m}^{2}$ to $25.9 \pm 1.5 \mathrm{~kg} / \mathrm{m}^{2}, \mathrm{p}<0.0005$, Table 2), and average HbAlc level (from $7.4 \pm 0.3 \%$ to $6.8 \pm 0.2 \%$, p $<0.005$, Figure 4). After three months of the intervention program termination (at 6 months after study initiation), the average HbAlc level returned to almost the same levels as it was at the pre-intervention stage (from $6.8 \pm 0.2 \%$ to $7.2 \pm 0.3 \%$, p $<0.05$, Figure 4). In usual care group, the average HbA1c level of the patients did not change significantly for six months, as shown in Figure 4, which confirmed that this intervention program was effective in decreasing HbAlc level.

The average FBG level had a tendency to decrease with intervention (from $134.7 \pm 12.5 \mathrm{mg} / \mathrm{dl}$ to $111.1 \pm 7.7 \mathrm{mg} / \mathrm{dl}$, 18\% decrease, Table 2), although not significantly. The total plasma cholesterol and HDL-cholesterol levels did not 
change significantly before and after intervention. The TG levels tended to decrease with intervention (from $134.6 \pm$ $24.9 \mathrm{mg} / \mathrm{dl}$ to $116.2 \pm 14.4 \mathrm{mg} / \mathrm{dl}, 14 \%$ decrease, Table 2 ), although not statistically significantly.

\section{Discussion}

In the present study, we used the telemedicine system using multimodal videophones as a tool to communicate bi-directionally, so as to create an environment in which diabetes patients can live without anxiety. The goal of this study was to test the feasibility and efficacy of an intervention program delivered via multimodal videophone. After a three-month intervention program, BW, BMI, and average HbA1c level decreased significantly. From the above results, we conclude that our novel telemedicine system is a useful, effective, and low-cost intervention that can improve the quality of life of patients with diabetes.

All participants in this study had diabetes that had been poorly controlled for many years despite repeated hospitalization for patient education about the condition under the direction of medical professionals. Thus, it is plausible that this novel intervention led to more effective glycemic control than the conventional approach, because of the reasons discussed below.

One reasons for the effectiveness of this study was that the program led to increased awareness of a good lifestyle among participants by making them record BW, compliance checks, walk counts, and remarks every day. Additionally, sharing the information with a health care professional once a week led to a decrease in BW, BMI, and HbA1c level. This is in line with literature showing that raising awareness of the disease and self-monitoring could have a beneficial effect on glycemic control [23, 24]. Besides, our multimodal videophone system, which is able to illustrate change in BW graphically, led the participants to success in self-management, because they could recognize the benefits and merits from visual feedback. We speculate that this intervention program was effective in increasing awareness of a good lifestyle - not only by making participants document their daily records, but also by convincing 
them that their lifestyle strongly correlates with their health status by showing a graph every time.

Another reason for the effectiveness of the program was the use of photos of the meals which the participants actually ate. The videophone was able to display attached photos of the meals and to add a note of caution on the touch panel in real time. Because we advised a patient with diabetes on the amount and types of food he or she ate by giving marks, calories, and adding a few words of caution on the screen directly, we could take realistic and specific approaches in dietary intervention. The patients could easily understand how to select and combine the food to control calorie intake, by receiving individual guidance using the attached pictures of the meals. Thus, they could set a realistic goal for weight loss. Providing patients with personalized and specific advice from diabetes care specialists gives rise to a beneficial result [25]. In this regard, the use of the videophone system, which focuses on patientsô education for self-management, provided an appropriate opportunity for patients with diabetes who have difficulty maintaining adequate glucose levels at home.

The third reason for the success of the program was the continuous intensive communication with a member of the medical staff for three months. There is no easy way to change a lifestyle over the years, and maintenance of desirable blood glucose levels is left to the self-management ability of the individual. Considering that type 2 diabetes patients return for follow-up visits once in one or two months, they must keep an eye on their blood glucose levels without medical professionalsôhelp in the interval between ambulatory practices. Previous studies have already revealed the effectiveness of frequent intervention. Pimazoni-Netto A et al. [26] showed that within a short span there is rapid improvement of glycemic control in diabetics using weekly intensive multifactorial intervention. Our present results are consistent with this research. However, regarding the frequency of the hospital visit, the usual care group presented had several visits to a clinic during the study, while the intervention group had weekly videophone sessions. Thus, it may be considered that the usual care group did not serve as an appropriate control, which is a limitation of our study. 
In the literature, similar comparative studies in which control groups were differently treated from the intervention

group [26] have been reported. Therefore, our comparison can be considered standard. Further, the difference of the intervention frequency is deeply associated with our study, in which the novelty of the research lies in the fact that home-care diabetics can receive helpful guidance from a member of the medical staff without having to make frequent hospital visits. As we would like to show the possibility that the multimodal videophone system is helpful as a means of providing lifestyle guidance at outpatient clinics, we selected diabetics with regular hospital visits as controls. The videophone-based intensive communication made it possible for the patients with diabetes who only visit the hospital once a month or once in two months to continuously acquire sufficient knowledge and encouragement by communicating with a health care professional. ICT-based videophone system made frequent counseling available to home-care diabetes patients.

In this study, we made a special effort to instruct participants to adhere to the adequate diet because diet therapy is an important approach for patients with diabetes, especially obese patients. The risk of developing diabetes appears to increase with increased levels of BMI [27, 28]. Thus, keeping a daily caloric count and any decrease in BMI toward the recommended range are expected to improve glycemic control. Our results support the theory that there is a correlation between decreased BMI and improved glycemic control. For participants in the intervention group, the average $\mathrm{HbAlc}$ level improved in parallel with decreased BMI, when compared with the readings at the start of the study. Additionally, the average HbAlc level, after three months of the intervention program termination (at six months after study initiation), returned to almost the same level as it was at the pre-intervention stage. Taken together, these results document that encouraging diabetic patients to become more aware of weight reduction is a realistic and effective approach.

After the intervention, many participants expressed a feeling of satisfaction about this videophone system. Some of 
the opinions are given below: ñTalking to the medical staff frequently through the videophone system played an important role in resolving issues regarding the diet, especially those regarding dairy products, on the spot.ò ñwe could easily understand how to select and combine the food to control calorie intake in our real life by receiving individual guidance using the attached pictures of the meals.òñThis videophone system is a helpful tool because it is hard for elderly people to visit the hospital frequently to receive outpatient treatment.ò From these comments, we believe that this videophone system can be useful from viewpoint of the patients.

There was no significant reduction of the average FBG level, although the average HbAlc level showed a significant decrease. This may be attributed to the fact that $\mathrm{HbAlc}$ is considered to reflect the average measure of blood glucose over the previous 12-week period better than FBG [29, 30]. Alternatively, this gives rise to the possibility that postprandial hyperglycemia may be improved by this intervention program. As stated above, we made a special effort to instruct participants to adhere to the adequate diet of well-balanced food including many vegetables, low carbohydrate, and low fat. It is known that an adequate diet, especially low-carbohydrate, improves postprandial blood glucose control [5] [31]. However, it is not clear whether the intervention actually influenced postprandial hyperglycemia which was not measured in this study. This possibility should be pursued in any future study.

TG levels tended to decrease after the three-month intervention program, although not significantly. We suppose that longer intervention periods might induce a significant decrease in this parameter.

In the present study, the system may or may not be useful for a long-term educational approach, since we did not focus on the factors which may affect the long-term effect in this study. To obtain long-term favorable effects, we suggest that this videophone system should be continued for a longer time even though the duration and frequency of communication are yet to be decided. We should consider it to maintain a favorable effect for a longer term; we are now planning to implement the next intervention program. 
In the future, the telemedicine approach will contribute to cost savings if this system is covered by insurance and used in daily practice. Currently, as there are about 550,000 latent nurses in Japan, we assume that they may be able to work as health care professionals who stay at home and communicate with patients through the Internet.

In conclusion, we showed that a three-month bi-directional intensive communication using the videophone-based system resulted in a significant decrease in BW, BMI, and average HbA1c level. The bi-directional communication using multimodal videophones can be useful as an auxiliary therapy for switching to a good lifestyle.

The results of the study show a potential strategy for diabetes care, which can be used as an alternative approach to conventional hospital visits in the near future.

\section{Acknowledgments}

We thank Hideyo Tsutsui from the Department of Sports Medicine, the University of Nagoya, for her valuable comments. We also thank the patients and their families for participating in this study. A part of this study was supported by the Grant-in-Aid for Young Scientists (B) (grant No. 21792305) from the Japanese Ministry of Education, Culture, Sports, Science, and Technology (MEXT); and the research grant from the UNIVERS foundation.

\section{References}

[1]. King H, Aubert RE, Herman WH. Global burden of diabetes, 1995-2025 - Prevalence, numerical estimates, and projections. Diabetes Care, 1998; 21 (9): 1414-1431.

[2]. Ministry of Health LaW. Outline of Results from 2007 National Health and Nutrition Survey. Tokyo.

[3]. Chan JCN, Malik V, Jia WP, Kadowaki T, Yajnik CS, Yoon KH, et al. Diabetes in Asia Epidemiology, 
Risk Factors, and Pathophysiology. Jama-J Am Med Assoc, 2009; 301 (20): 2129-2140.

[4]. Schmidt MI, Duncan BB. Diabesity: An inflammatory metabolic condition. Clin Chem Lab Med, 2003; 41 (9): $1120-1130$.

[5]. Kubota M, Koshinaka K, Kawata Y, Koike T, Oshida Y. Effects of continuous low-carbohydrate diet after long-term exercise on GLUT-4 protein content in rat skeletal muscle. Horm Metab Res, $2008 ; 40$ (1): 24-28.

[6]. Kubota M, Nagasaki M, Tokudome M, Shinomiya Y, Ozawa T, Sato Y. Mechanical horseback riding improves insulin sensitivity in elder diabetic patients. Diabetes Res Clin Pr, 2006; 71 (2): 124-130.

[7]. Klein S, Sheard NF, Pi-Sunyer X, Daly A, Wylie-Rosett J, Kulkarni K, et al. Weight management through lifestyle modification for the prevention and management of type 2 diabetes: Rationale and strategies. Diabetes Care, 2004; 27 (8): 2067-2073.

[8]. Matvienko OA, Hoehns JD. A Lifestyle Intervention Study in Patients with Diabetes or Impaired Glucose Tolerance: Translation of a Research Intervention into Practice. J Am Board Fam Med, 2009; 22 (5): 535-543.

[9]. Wing RR, Blair EH, Bononi P, Marcus MD, Watanabe R, Bergman RN. Caloric Restriction Per Se Is a Significant Factor in Improvement in Glycemic Control and Insulin Sensitivity during Weight-Loss in Obese Niddm Patients. Diabetes Care, 1994; 17 (1): 30-36.

[10]. Pi-Sunyer FX, Maggio CA, McCarron DA, Reusser ME, Stern JS, Haynes RB, et al. Multicenter randomized trail of a comprehensive prepared meal program in type 2 diabetes. Diabetes Care, 1999; 22 (2): 191-197.

[11]. Shibayama T, Kobayashi K, Takano A, Kadowaki T, Kazuma K. Effectiveness of lifestyle counseling by certified expert nurse of Japan for non-insulin-treated diabetic outpatients: a 1-year randomized controlled trial. Diabetes Res Clin Pr, 2007; 76 (2): 265-268.

[12]. Hori M KM, Ando K, Kihara T, Takahashi R, Kinoshita A. The effect of videophone communication 
(with skype and webcam) for elderly patients with dementia and their caregivers. Gan To Kagaku Ryoho, 2009; 35

(1): $36-38$.

[13]. Harvey-Berino J, Pintauro S, Buzzell P, Gold EC. Effect of Internet support on the long-term maintenance of weight loss. Obes Res, 2004; 12 (2): 320-329.

[14]. Eakin EG, Reeves MM, Marshall AL, Dunstan DW, Graves N, Healy GN, et al. Living Well with Diabetes: a randomized controlled trial of a telephone-delivered intervention for maintenance of weight loss, physical activity and glycaemic control in adults with type 2 diabetes. Bmc Public Health, 2010; 10 -.

[15]. Sherwood NE, Jeffery RW, Pronk NP, Boucher JL, Hanson A, Boyle R, et al. Mail and phone interventions for weight loss in a managed-care setting: weigh-to-be 2-year outcomes. Int J Obesity, 2006; 30 (10): $1565-1573$

[16]. Noh JH, Cho YJ, Nam HW, Kim JH, Kim DJ, Yoo HS, et al. Web-Based Comprehensive Information System for Self-Management of Diabetes Mellitus. Diabetes Technol The, 2010; 12 (5): 333-337.

[17]. Ueno M, Takeuchi S, Oshiro A, Shinada K, Ohara S, Kawaguchi Y. Association between diabetes mellitus and oral health status in Japanese adults. Int J Oral Sci, 2010; 2 (2): 82-89.

[18]. Czaja SJ, Charness N, Fisk AD, Hertzog C, Nair SN, Rogers WA, et al. Factors predicting the use of technology: findings from the Center for Research and Education on Aging and Technology Enhancement (CREATE). Psychol Aging, 2006; 21 (2): 333-352.

[19]. Nguyen NT, Nguyen XMT, Lane J, Wang P. Relationship Between Obesity and Diabetes in a US Adult Population: Findings from the National Health and Nutrition Examination Survey, 1999-2006. Obes Surg, 2011; 21 (3): $351-355$.

[20]. Society JD. Guideline for treatment of diabetes mellitus 
(http://www.jds.or.jp/jds_or_jp0/data/guideline/021-027.pdf).

[21]. obesity Jsftso. Guideline for treatment of obesity 2006, Japan society for the study of obesity, Tokyo, 2006.

[22]. Nakajima Y, Sato K, Sudo M, Nagao M, Kano T, Harada T, et al. Practical Dietary Calorie Management,

Body Weight Control and Energy Expenditure of Diabetic Patients in Short-term Hospitalization. J Atheroscler

Thromb, 2010; 17 (6): 558-567.

[23]. Reynolds LR, Anderson JW. Practical office strategies for weight management of the obese diabetic individual. Endocr Pract, 2004; 10 (2): 153-159.

[24]. Chan WB, Chan JC, Chow CC, Yeung VT, So WY, Li JK, et al. Glycaemic control in type 2 diabetes: the impact of body weight, beta-cell function and patient education. Qjm, 2000; 93 (3): 183-190.

[25]. lizuka Y, Ohashi K, Tsukamoto K, Ueki K, Kadowaki T. Education and management of diabetes at The University of Tokyo Hospital. J Diabetes, 2011; 3 (2): 104-108.

[26]. Pimazoni-Netto A, Rodbard D, Zanella MT, Grp DEC. Rapid Improvement of Glycemic Control in Type 2 Diabetes Using Weekly Intensive Multifactorial Interventions: Structured Glucose Monitoring, Patient Education, and Adjustment of Therapy-A Randomized Controlled Trial. Diabetes Technol The, 2011; 13 (10): 997-1004.

[27]. Colditz GA, Willett WC, Stampfer MJ, Manson JE, Hennekens CH, Arky RA, et al. Weight as a risk factor for clinical diabetes in women. Am J Epidemiol, 1990; 132 (3): 501-513.

[28]. Knowler WC, Pettitt DJ, Savage PJ, Bennett PH. Diabetes incidence in Pima indians: contributions of obesity and parental diabetes. Am J Epidemiol, 1981; 113 (2): 144-156.

[29]. Rohlfing CL, Wiedmeyer HM, Little RR, England JD, Tennill A, Goldstein DE. Defining the relationship between plasma glucose and $\mathrm{HbA}(1 \mathrm{c})$ : analysis of glucose profiles and $\mathrm{HbA}(1 \mathrm{c})$ in the Diabetes Control and Complications Trial. Diabetes Care, 2002; 25 (2): 275-278. 
[30]. Goldstein DE, Little RR, Wiedmeyer HM, England JD, McKenzie EM. Glycated hemoglobin: methodologies and clinical applications. Clin Chem, 1986; 32 (10 Suppl): B64-70.

[31]. De Natale C, Annuzzi G, Bozzetto L, Mazzarella R, Costabile G, Ciano O, et al. Effects of a Plant-Based High-Carbohydrate/High-Fiber Diet Versus High-Monounsaturated Fat/Low-Carbohydrate Diet on Postprandial Lipids in Type 2 Diabetic Patients. Diabetes Care, 2009; 32 (12): 2168-2173.

Fig. 1 Situation of intercommunication between a patient with diabetes and a nurse through the videophone system.

The patients in the intervention group communicated bi-directionally on a one-to-one basis with a staff nurse through the videophone system for 30 minutes, once a week

Fig. 2 A real screen with writing marks, calories, and a few words of caution written by a nurse so that a patient with diabetes learns naturally to have an appropriate diet.

The staff nurse advised the patients on the amount and types of food that they should eat by drawing marks, nothing the approximate calorie contents of the meal, and by writing a few comments on a display directly

Fig.3 Effects of the bi-directional communication via videophone system on the average body weight

The 3-month intervention program resulted in a significant decrease in the body weight $(-3.3 \pm 0.6 \%$, $\mathrm{p}<0.0005$ ). After 3 months of the intervention program termination, the body weight returned to almost the same levels of pre-intervention $(\mathrm{p}<0.005)$.

Values are means \pm SE for ten subjects with type 2 diabetes. 
$* * \mathrm{p}<0.0005$ versus before intervention. $* \mathrm{p}<0.005$ versus 3 -month after intervention.

Fig. 4 Effects of the bi-directional communication via videophone system on the average HbA1c level

The 3-month intervention program resulted in a significant decrease in the average HbA1c level (from 7.4 $\pm 0.3 \%$ to $6.8 \pm 0.2 \%, \mathrm{p}<0.005)$. After 3 months of the intervention program termination, the average HbA1c level returned to almost the same levels of pre-intervention (from $6.8 \pm 0.2 \%$ to $7.2 \pm 0.3 \%, \mathrm{p}<0.05$ ).

.... Changes in HbA1c level of the control patients who were treated on an outpatient basis as usual. The average $\mathrm{HbA1C}$ level of the patients did not change significantly for six months.

Values are means $\pm \mathrm{SE}$.

** $\mathrm{p}<0.005$ versus before intervention. * $\mathrm{p}<0.05$ versus 3 -month after intervention. 
Table 1. Characteristics of the patients at baseline

\begin{tabular}{|c|c|c|c|c|c|c|c|c|c|c|c|}
\hline & $\begin{array}{l}\text { Age } \\
\text { (yrs) }\end{array}$ & $\begin{array}{l}\text { Sex } \\
(M / F)\end{array}$ & $\begin{array}{l}\text { BW } \\
(\mathrm{kg})\end{array}$ & $\begin{array}{c}\text { BMI } \\
\left(\mathrm{kg} / \mathrm{m}^{2}\right)\end{array}$ & $\begin{array}{c}\text { DM } \\
\text { duration } \\
(y r s)\end{array}$ & $\begin{array}{c}\text { FBG } \\
(\mathrm{mg} / \mathrm{dl})\end{array}$ & $\begin{array}{c}\mathrm{HbA} 1 \mathrm{C} \\
(\%)\end{array}$ & $\begin{array}{c}\mathrm{TG} \\
(\mathrm{mg} / \mathrm{dl})\end{array}$ & $\begin{array}{c}\text { Total - } \\
\text { CHO } \\
(\mathrm{mg} / \mathrm{dl})\end{array}$ & $\begin{array}{c}\text { HDL- } \\
\mathrm{CHO} \\
\text { (mg/dl) }\end{array}$ & $\begin{array}{c}\text { LDL- } \\
\mathrm{CHO} \\
(\mathrm{mg} / \mathrm{dl})\end{array}$ \\
\hline Intervention group & $63 \pm 2$ & $4 / 6$ & $69.0 \pm 5.6$ & $26.8 \pm 1.5$ & $14 \pm 3$ & $134.7 \pm 12.5$ & $7.4 \pm 0.3$ & $134.6 \pm 24.9$ & $183.7 \pm 12.0$ & $51.1 \pm 4.5$ & $100.1 \pm 7.5$ \\
\hline Usual care group & $65 \pm 3$ & $4 / 6$ & $61.5 \pm 2.4$ & $24.6 \pm 0.9$ & $16 \pm 3$ & $157.0 \pm 18.7$ & $7.5 \pm 0.2$ & $106.6 \pm 20.7$ & $185.3 \pm 9.1$ & $51.9 \pm 4.0$ & $101.8 \pm 7.8$ \\
\hline
\end{tabular}

Values are means \pm SE for subjects with type 2 diabetes. 


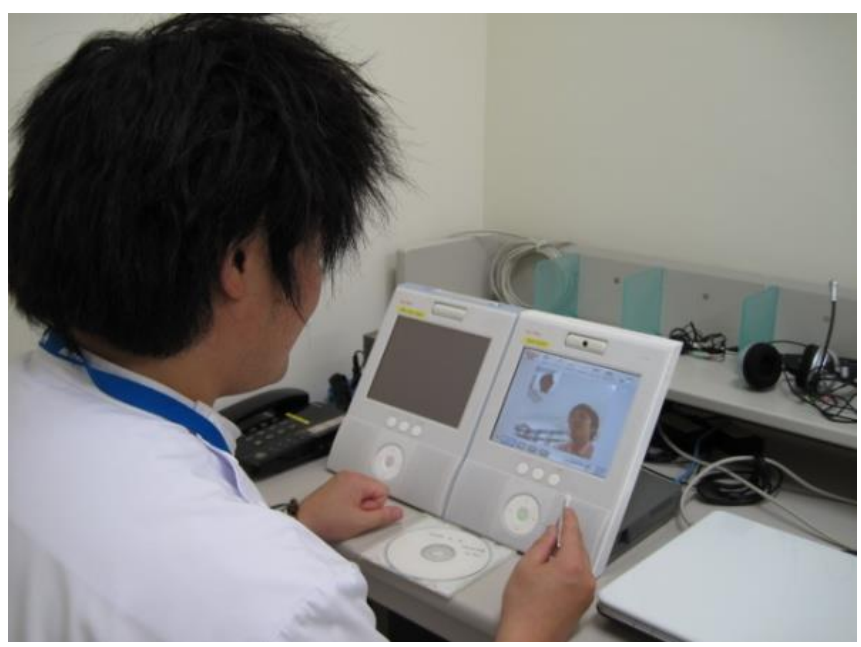




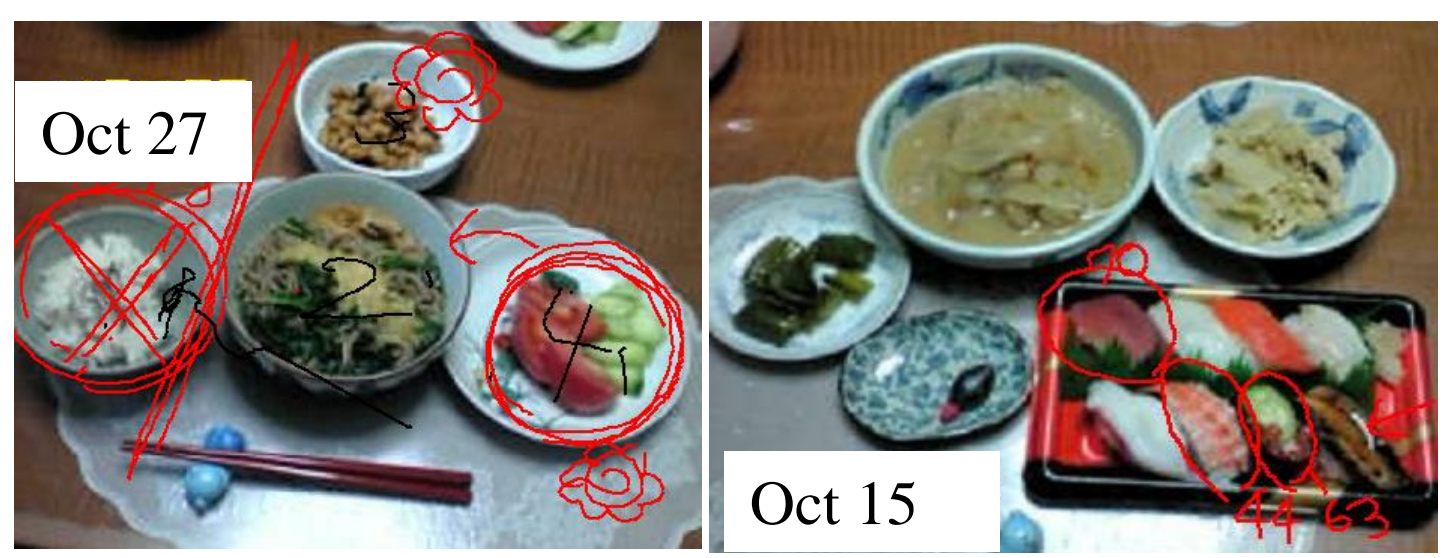




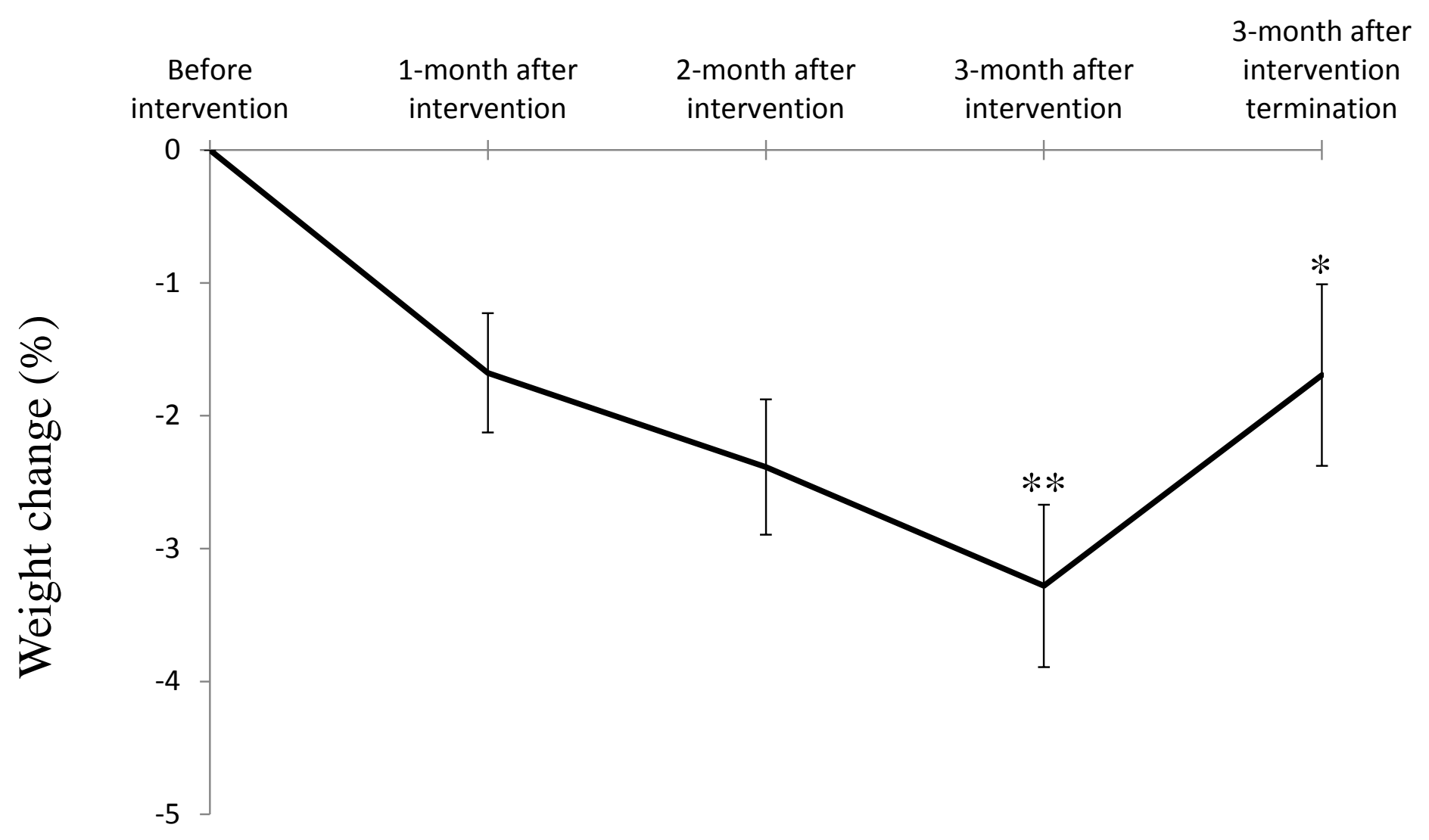


Table 2. Characteristics of sample at baseline and 3 month after intervention and 3 month after intervention termination in the intervention group

\begin{tabular}{|c|c|c|c|c|c|}
\hline & before intervention & $\begin{array}{l}3 \text { month after } \\
\text { intervention }\end{array}$ & $\begin{array}{c}\mathrm{p} \text { value } \\
\text { (vs. before } \\
\text { intervention) }\end{array}$ & $\begin{array}{c}3 \text { month after } \\
\text { intervention } \\
\text { termination }\end{array}$ & $\begin{array}{c}\text { p value } \\
\text { (vs. } 3 \text { month after } \\
\text { intervention) }\end{array}$ \\
\hline Body Weight (Kg) & $69 \pm 5.6$ & $66.9 \pm 5.6$ & $<0.0005$ & $67.9 \pm 5.7$ & $<0.005$ \\
\hline $\mathrm{BMI}(\mathrm{Kg} / \mathrm{m} 2)$ & $26.8 \pm 1.5$ & $25.9 \pm 1.5$ & $<0.0005$ & $26.4 \pm 1.5$ & $<0.005$ \\
\hline $\begin{array}{l}\text { Fasting glucose } \\
(\mathrm{mg} / \mathrm{dl})\end{array}$ & $134.7 \pm 12.5$ & $111.1 \pm 7.7$ & 0.1288 & $120.2 \pm 15$ & 0.5969 \\
\hline $\mathrm{HbA1C}(\%)$ & $7.4 \pm 0.3$ & $6.8 \pm 0.2$ & $<0.005$ & $7.2 \pm 0.3$ & $<0.05$ \\
\hline $\begin{array}{l}\text { Triglyceride } \\
\text { (mg/dl) }\end{array}$ & $134.6 \pm 24.9$ & $116.2 \pm 14.4$ & 0.4133 & $158.2 \pm 30.9$ & 0.0637 \\
\hline $\begin{array}{l}\text { Total-CHO } \\
(\mathrm{mg} / \mathrm{dl})\end{array}$ & $183.7 \pm 12$ & $190.5 \pm 12$ & 0.2213 & $184.7 \pm 12.4$ & 0.5012 \\
\hline $\begin{array}{l}\text { HDL-CHO } \\
(\mathrm{mg} / \mathrm{dl})\end{array}$ & $51.1 \pm 4.5$ & $54.8 \pm 5.1$ & 0.2349 & $54.7 \pm 5.1$ & 0.9714 \\
\hline LDL-CHO (mg/dl) & $100.1 \pm 7.5$ & $106.1 \pm 8.2$ & 0.2269 & $101.1 \pm 8.5$ & 0.3786 \\
\hline
\end{tabular}

Values are means \pm SE for ten subjects with type 2 diabetes. 


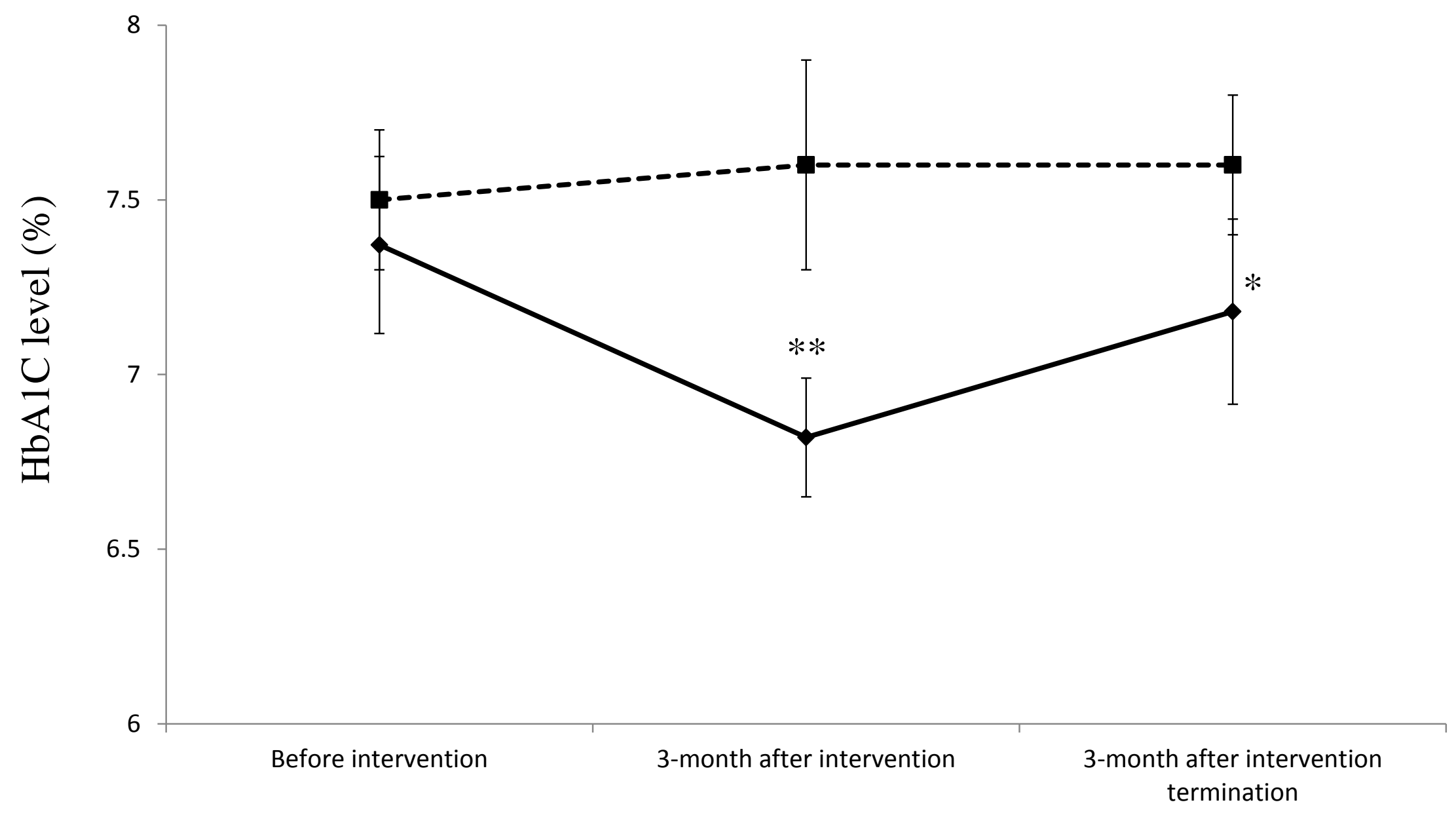

